\title{
PENGARUH DOSIS BIONEMATISIDA JAMUR Purpureocillium lilacinum (Syn. Paecilomyces lilacinus) ISOLAT B01TG BERBAHAN PEMBAWA LIMBAH PERTANIAN TERHADAP KEEFEKTIFANNYA DALAM MENGENDALIKAN Meloidogyne spp.
}

\section{THE EFFECT OF BIONEMATICIDE FUNGI Purpureocillium lilacinum (Syn. Paecilomyces lilacinus) BO1TG ISOLATE WITH AGRICULTURAL WASTE CARRIER MATERIALS ON THEIR EFFECTIVENESS WITHIN CONTROL Meloidogyne spp.}

\author{
A. Fiandani ${ }^{1}$, I G. Swibawa ${ }^{2}$, Y. Fitriana ${ }^{2} \&$ Purnomo $^{2}$ \\ ${ }^{1}$ Jurusan Agroteknologi, Fakultas Pertanian, Universitas Lampung, Bandar Lampung, Indonesia \\ ${ }^{2}$ Jurusan Proteksi Tanaman, Fakultas Pertanian, Universitas Lampung, Bandar Lampung, Indonesia \\ *Email:ambar.fiandani239@gmail.com \\ * Corresponding Author, Diterima: 8 Feb. 2021, Direvisi: 14 Apr. 2021, Disetujui: 5 Mei 2021
}

\begin{abstract}
This study aims to study the effect of Purpurecilum lilacinum (Syn. Paecilomyces lilacinus) Bionematicide fungus isolate from B01TG made from agricultural waste carriers on its effectiveness in controlling Rook Knot Nematodes (Meloidogyne spp.) infestation. This research was conducted in February-June 2019 in the greenhouse of the Faculty of Agriculture, University of Lampung. The Completely Randomized Design (CRD) consisting of 5 treatment levels of bionematicide doses of $5 \mathrm{~g}, 10 \mathrm{~g}, 20 \mathrm{~g}$ and $40 \mathrm{~g} / \mathrm{polybag}$ and $0 \mathrm{~g}$ as controls was applied. Each treatment was repeated 5 times. Tomato plants infested with 2000 nematode eggs were treated with bionematicide 3 days before transplanting. Plant growth data which included plant height, number of leaves, plant biomass and production, as well as root damage level were analyzed with analyses of variance and the mean separation were analyzed with the Least Significant Difference test (LSD) at the 5\% significance level. The results showed that dosage of bionematicide tested affected plant growth and root damage. The growth of plants treated with $40 \mathrm{~g}$ of bionematicide was better than the growth of plants treated with lower dose bionematicide respectively. The root damage of tomato plants due to Meloidogyne spp. infestation on plant that were given $20 \mathrm{~g}$ and $40 \mathrm{~g}$ of bionematicides treatments were lower than the root damage of plants that were treated with lower dosage of bionematicide respectively.
\end{abstract}

Keywords: Bionematicide, Meloidogyne spp., Purpureocilium lilacinum

\section{ABSTRAK}

Penelitian ini bertujuan untuk mempelajari pengaruh dosis bionematisida jamur Purpurecilum lilacinum (Syn. Paecilomyces lilacinus) isolat B01TG berbahan pembawa limbah pertanian terhadap keefektifannya untuk mengendalikan serangan nematoda puru akar Meloidogyne spp. Percobaan yang berlangsung bulan Februari - Juni 2019 di rumah kaca Fakultas Pertanian Universitas Lampung, menggunakan Rancangan Acak Lengkap (RAL), dengan 5 perlakuan tingkat dosis bionematisida dan 5 ulangan. Dosis bionematisida yang diuji yaitu $0 \mathrm{~g}$, $5 \mathrm{~g}, 10 \mathrm{~g}, 20 \mathrm{~g}$ dan $40 \mathrm{~g}$ per tanaman. Bionematiaida diaplikasikan 3 hari sebelum tanaman tomat ditransplanting. 
Satu minggu setelah transplanting, tanaman tomat kemudian diinfestasi 2000 telur nematoda puru akar. Data pertumbuhan tanaman yang meliputi tinggi tanaman, jumlah daun, bobot biomassa basah dan produksi, serta tingkat kerusakan akar dianalisis ragam dan dilanjutkan dengan pemisahan nilai tengah menggunakan uji BNT pada taraf nyata 5\%. Hasil penelitian menunjukkan bahwa dosis bionematisida mempengaruhi pertumbuhan tanaman dan kerusakan akar. Pertumbuhan tanaman yang diberi perlakuan $40 \mathrm{~g}$ bionematisida lebih baik daripada pertumbuhan tanaman yang diberi bionematiaida dengan dosis yang lebih rendah. Kerusakan akar tanaman tomat akibat serangan Meloidogyne spp. lebih rendah pada tanaman tomat yang diberikan perlakuan $20 \mathrm{~g}$ dan $40 \mathrm{~g}$ daripada kerusakan akar tanaman yang diberi perlakuan bionematisida dengan dosis yang lebih rendah.

Kata kunci : Bionematisida, Purpureocilium lilacinum, Meloidogyne spp.

\section{PENDAHULUAN}

Nematoda puru akar (Meloidogyne spp.) merupakan salah satu organisme pengganggu tanaman (OPT) penting tanaman hortikultura dan tanaman pangan di Indonesia. Serangan nematoda puru akar (NPA) merupakan salah satu hambatan produksi tanaman, terutama sayuran di Indonesia. Gejala serangan NPA pada tanaman tampak pada bagian tanaman di atas dan di bawah tanah. Tanaman terserang nematoda puru akar (NPA) umumnya menunjukkan gejala daun menguning, pertumbuhan terhambat, kerdil, lebih cepat layu pada siang hari. Gejala serangan NPA pada bagian tanaman di bawah permukaan tanah menunjukkan adanya hipertropi dan hiperplasia pada jaringan akar sehingga terbentuk puru. Puru akar terbentuk karena pembelahan dan pembesaran sel secara berlebihan pada jaringan perisikel tanaman yang diserang NPA (Agrios, 2005). Gangguan pada akar tanaman ini mempengaruhi penyerapan air dan unsur hara dari dalam tanah dan transportasinya ke bagian tanaman lainnya.

Pengendalian NPA pada umumnya menggunakan nematisida kimiawi yang diaplikasikan pada tanah. Metode ini dikritik oleh banyak pihak karena menyebabkan pencemaran air tanah (Calvet et al., 2001). Polusi air tanah dan daya racun yang tinggi menimbulkan banyak masalah lingkungan. Selain itu, kenyataan bahwa penggunaan nematisida kimiawi tidak ekonomis sehingga menyebabkan penghentian pemasaran beberapa nematisida di negara-negara berkembang (Aksoy \& Mennan, 2004). Oleh karena itu, perhatian orang mulai beralih kepada metode pengendalian alternatifyang efektif, efisien, tetapi aman terhadap lingkungan. Salah satu teknik pengendalian seperti itu pengendalian hayati.

Di lingkungannya, NPAmemiliki banyak musuh alami, diantaranya jamur antagonis yang dapat dimanfaatkan sebagai agensia pengendalian hayati. Menurut Mulyadi et al. (1991 dalam Winarto et al., 2017), jamur P. lilacinum (Syn. P. lilacinus) yaitu parasit telur, larva dan dewasa NPA efektif mengendalikan nematoda parasit tumbuhan pada berbagai jenis tanaman. Jamur P. lilacinum telah banyak digunakan sebagai agensia pengendalian hayati karena jamur ini bersifat kosmopolitan dan mampu mengkoloni bahan organik sisa tanaman dan bahan lainnya di dalam tanah.

Salah satu metode pengendalian NPA dengan jamur antagonis adalah penggunaan bionematisida 
berbahan aktifjamur. Banyak jenis bionematisida yang beredar di pasaran, namun belum tersedia informasi mengenai penggunaan bionematisida yang dibuat dari jamur antagonis nematoda lokal menggunakan limbah pertanian padat sebagai bahan pembawanya. Penelitian ini bertujuan untuk mempelajari penggunaan bionematisida jamur P. lilacinum (Syn. P. lilacinus) isolat B01TG asal Tanggamus berbahan pembawa limbah pertanian untuk mengendalikan NPA (Meloidogyne spp.).

\section{BAHAN DAN METODE}

Percobaan yang berlangsung bulan Februari Juni 2019 dilaksanakan di rumah kaca Fakultas Pertanian, Unversitas Lampung. Percobaan menggunakan Rencana Acak Lengkap (RAL) yang terdiri dari 5 perlakuan dan 5 ulangan. Dosis bionematisida yang dicobakan yaitu berturutan $0 \mathrm{~g}, 5$ g, 10 g, 20 g, dan $40 \mathrm{~g}$ bionematisida tiap polybag berisi media tanam tanah steril 2,5 kg. Aplikasi bionematisida dilakukan 3 hari sebelum transplanting bibit tomat. Tomat varietas Victory yang diinfestasi nematoda puru akar Meloidogyne spp. digunakan sebagai tanaman indikator.

Jamur P. lilacinum (Syn. P. lilacinus) isolat B01TG bahan bionematisida diremajakan pada media PSA, kemudian diperbanyak mengunakan media beras. Perbanyakan jamur P. lilacinum dilakukan di Labotarorium Bioteknologi, Fakultas Pertanian Unila. Biakan murni jamur P. lilacinum (Syn. P. lilacinus) isolat B01TG merupakan koleksi Laboratorium Ilmu Hama Tumbuhan yang diisolasi dari akar tanaman jambu biji kristal milik petani di Tanggamus (Haryani, 2018).
Jamur diinkubasikan selama 2 minggu agar tumbuh merata pada media beras. Bionematisida dibuat dari limbah pertanain kering yaitu 180 bagian bonggol pisang, 180 bagian kulit ubi ubikayu, 38 bagian beras berjamur P. lilacinum (Syn. P. lilacinus) isolat B01TG dan 2 bagian kulit udang. Media tanam terdiri dari campuran tanah dan pasir (3:1) steril dengan cara dikukus menggunakan dandang selama 4 jam. Setiap polybag diisi $\pm 2,5 \mathrm{~kg}$ media tanam.

Telur nematoda dikoleksi dari akar jambu biji Kristal terserang nematoda dari PT NTF, Lampung Timur. Akar terserang NPA dicuci dan dipotong \pm 1 $2 \mathrm{~cm}$, kemudian dimasukkan ke erlenmeyer berisi larutan klorok (NaOCl) 1\%, kemudian dikocok selama \pm 10 menit sehingga telur lepas dari akar. Suspensi telur NPA dibilas dengan air mengalir dengan saringan $38 \mu \mathrm{m}$ sampai klorok hilang yang ditandai dengan tidak tercium baunya. Telur dalam suspensi dihitung di bawah mikroskop stereo binokuler menggunakan cawan Petri berbaris untuk menentukan jumlah telur tiapml suspensi. Infestasi telur nematoda pada tanaman dilakukan ketika tanaman berumur 3 minggu setelah transplanting. Setiap tanaman diinfestasi 2000 telur menggunakan mikropipet.

Perawatan tanaman meliputi penyiraman, pemupukan, pemasangan ajir, dan pengendalian gulma. Penyiraman tanaman dilakukan setiap pagi dan sore menggunakan air mengalir. Pemberian pupuk majemuk NPK (15:15:15) dengan dosis $30 \mathrm{~g} /$ tanaman. Pemberian pupuk dilakukan secara bertahap, yaitu ketika tanaman berumur 2 mst, tanaman berumur 5 mst, dan tanaman berumur 8 mst yaitu masing-masing 10 g. Pemasangan ajir bertujuan untuk mencegah tanaman tomat roboh. Pengendalian gulma dilakukan 
dengan cara manual yaitu gulma yang tumbuh dicabut dan dibuang.

Variabel yang diamati meliputi pertumbuhan tanaman yang terdiri dari tinggi tanaman, jumlah daun, biomassa dan produksi buah, serta kerusakan akar. Kerusakan akar tanaman diukur menggunakan skala puru akar Zeck (1971, dalam Hay et al., 2014) yaitu skala 0 sampai 10 (Tabel 1).

Pertumbuhan tanaman yang diamati meliputi tinggi tanaman, jumlah daun, biomassa dan produksi buah. Tinggi tanaman diukur dari pangkal batang sampai ujung tunas yang baru tumbuh dengan menggunakan meteran. Pengamatan jumlah daun dilakukan dengan menghitung seluruh daun per tanaman. Bobot brangkasan tanaman meliputi brangkasan tajuk dan akar. Setelah panen yaitu ketika tanaman berumur 98 hst tanaman dibongkar, bagian buah dihitung, bagian tajuk dipotong dan bagian akar diambil. Bobot berangkasan basah diukur menggunakan timbangan analitik (KERN) dengan satuan g per tanaman.

\section{HASIL DAN PEMBAHASAN}

\section{Pertumbuhan dan Produksi Tanaman}

Hasil pengamatan menunjukkan pertumbuhan tanaman yang meliputi tinggi, jumlah daun, biomassa yaitu bobot brangkasan basah dan produksi tanaman

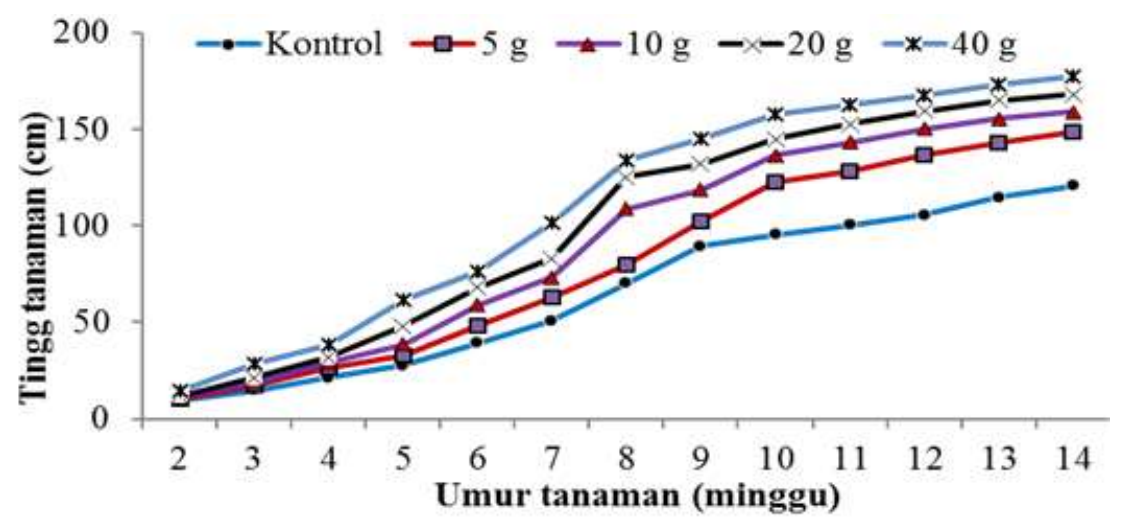

Gambar 1. Tinggi tanaman tomat terinfestasi NPA yang diberi perlakuan bionematisida jamur P. lilacinum (Syn. P. lilacinus) isolat BO1TG berbahan pembawa limbah pertanian.

Tabel 1. Tingkat kerusakan akar pada tanaman tomat berdasarkan skala puru akar (Zeck 1971 dalam Hay et al., 2014)

\begin{tabular}{cl}
\hline Skala & \multicolumn{1}{c}{ Kriteria Terbentuknya Puru Akar } \\
\hline 0 & Sistem akar sehat tanpa puru \\
1 & Terdeteksi sedikit sekali puru kecil (2\%) dengan pengamatan seksama \\
2 & Sangat jelas tampak telah terbentuk banyak puru kecil (4\%). \\
3 & Terdapat banyak puru kecil, beberapa menyatu dan tumbuh menjadi lebih besar tetapi belum \\
4 & mempengaruhi fungsi akar \\
5 & Terdapat banyak puru kecil dan beberapa puru besar, tetapi sebagian besar akar masih berfungsi. \\
6 & Puru membesar di bagian akar utama dan sekelilingnya. \\
7 & Sebesar 75\% sistem perakaran tidak berfungsi karena puru yang parah. \\
8 & Tidak ada akar sehat tersisa, pertumbuhan pucuk terganggu, tetapi tanaman masih tampak hijau. \\
9 & Sistem perakaran dan puru membusuk, tanaman mati. \\
10 & Tanaman dan akar mati. \\
\hline
\end{tabular}


tomat yang diinfestasi NPA dipengaruhi oleh dosis bionematisida jamur P. lilacinum (Syn. P. lilacinus) isolat BO1TG berbahan pembawa limbah pertanian. Secara umum pertumbuhan tanaman yang diberi perlakuan bionematisida dosis tinggi lebih baik daripada pertumbuhan tanaman yang diberi perlakuan bionematisida dosis rendah termasuk tanaman kontrol.

Tinggi tanaman tomat pada umur 2 minggu setelah transplanting (MST) meningkat mengikuti umurnya (Gambar 1). Hasil analisis ragam menunjukkan bahwa tinggi tanaman dipengaruhi oleh perlakuan bionematisida, yang berarti pertumbuhan tanaman tomat yang diinfestasi NPA dipengaruhi oleh perlakuan dosis bionematisida. Tanaman yang diberi perlakuan bionematisida 40 g per tanaman lebih tinggi daripada tanaman kontrol dan tanaman yang diberi perlauan bionematisida dosis 5-10 g pertanaman. Dengan kata lain, tanaman tomat yang diinfestasi NPA (Meloidogyne spp.) dan diberi perlakuan bionematisida, pertumbuhannya lebih baik daripada tanaman tomat yang tidak diberi perlakuan bionematisida atau diberi perlakuan dengan dosis rendah. Pada penelitian ini aplikasi bionematisida berbahan aktif $P$. lilacinum (Syn. P. lilacinus) tampak efektif mengendalikan NPA. Menurut Stirling (2014) jamur ini mampu menghasilkan enzim khitinolitik yang mematikan nematoda. Selain mematikan nematoda, kitin terdegradasi menghasilkan senyawa yang mengandung nitrogen $(\mathrm{N})$ yaitu sumber nutrisi sehingga dapat menyuburkan tanaman (Spiegel, 1989 dalam Collange et al., 2011).

Jumah daun tanaman bertambah seiring bertambahnya umurnya (Gambar 2). Hasil analisis ragam menunjukkan bahwa perlakuan bionematisida mempengaruhi jumlah daun. Tanaman terinfestasi NPA mengalami gangguan pada sistem perakarannya sehingga tidak optimum menyerap air dan unsur hara. Akibatnya, pertumbuhan tanaman terhambat dan tidak dapat melakukan proses fotosintesis secara optimum, daun layu dan menguning hingga gugur(Dropkin, 1991). Namun demikian, pemberian bionematisida $40 \mathrm{~g}$ pertanaman pada tanaman terinfestasi NPA ini dapat melindungi tanaman sehingga jumlah daunnya lebih banyak daripada tanaman kontrol yang tidak diberi

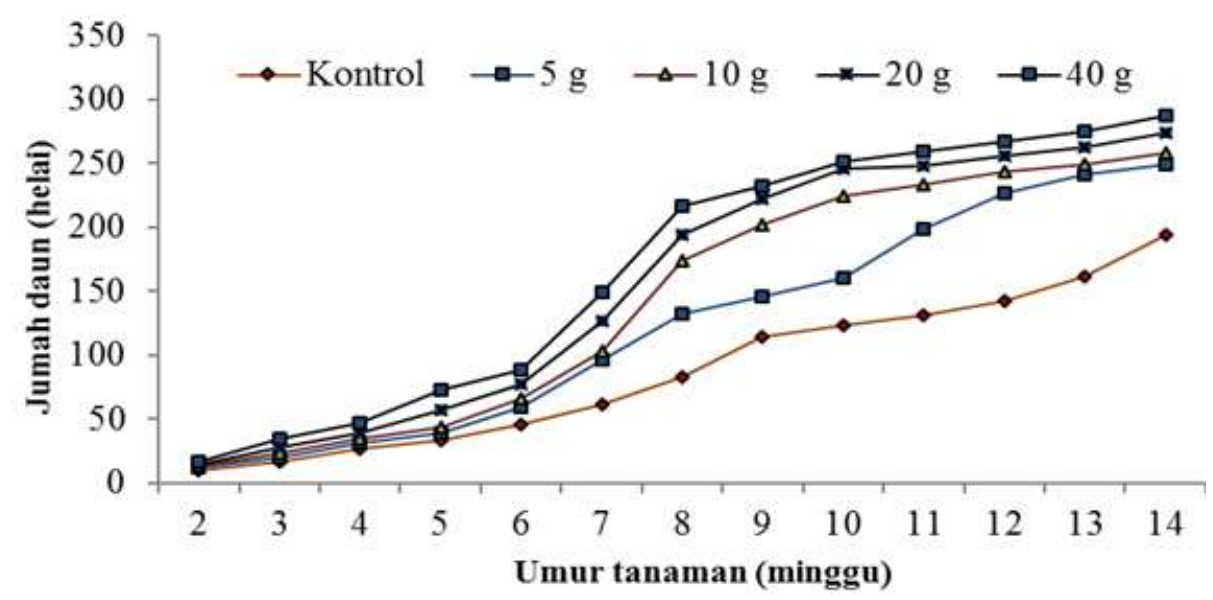

Gambar 2. Jumlah daun tanaman tomat terinfestasi NPA yang diberi perlakuan bionematisida jamur P. lilacinum (Syn. Paecilomyces lilacinus) isolat BO1TG berbahan pembawa limbah pertanian. 
perlakuan bionematisida dan tanaman yang diberi perlakuan bionematisida dengan dosis 5-20 g per tanaman (Gambar 2). Data ini menunjukkan bahwa perlakuan bionematisida jamur P. lilacinum (Syn. $P$. lilacinus) isolat BO1TG berbahan pembawa limbah pertanian dapat melindungi tanaman dari gangguan nematoda sehingga pertumbuhan tanaman terutama jumlah daunnya tetap tinggi.

Bobot brangkasan basah tajuk dan akar juga dipengaruhi oleh perlakuan bionematisida (Gambar 3). Bobot brangkasan basah tajuk (BBT) tanaman yang diberi perlakuan bionematisida dengan dosis $5 \mathrm{~g}, 10$ g, 20 g dan 40 g per tanaman dan tanaman kontrol berbeda nyata. BBT tanaman yang diberi perlakuan bionematisida $40 \mathrm{~g}$ mencapai $186 \mathrm{~g}$, lebih tinggi daripada BBT tanaman yang diberi perlakuan bionematiaida $10 \mathrm{~g}$ per tanaman yaitu $150 \mathrm{~g}$ dan tanaman kontrol yang hanya mencapai 117 g. Ada kecenderungan bahwa BBT tanaman meningkat seiring peningkatan perlakuan dosis bionematisida. Hal yang sebaliknya terjadi pada bobot brangkasan basah akar (BBA) tanaman. BBA tanaman menurun seiring dengan peningkatan dosis bionematisida yang diberikan. Ada indikasi BBA meningkat dengan meningkatnya pembentukan puru akar karena serangan NPA. Terbentuknya puru yang berukuran besar akibat

Tabel 2. Jumlah buah tomat yang diinfestasi NPA dan diberi perlakuan bionematisida jamur P. lilacinum (Syn. $P$. lilacinus) isolat BO1TG berbahan pembawa limbah pertanian.

\begin{tabular}{cc}
\hline Perlakuan & Jumlah buah/tnmn \\
\hline Kontrol & $5,2 \mathrm{e}$ \\
$5 \mathrm{~g}$ & $12,4 \mathrm{~d}$ \\
$10 \mathrm{~g}$ & $18,2 \mathrm{c}$ \\
$20 \mathrm{~g}$ & $24 \mathrm{~b}$ \\
$40 \mathrm{~g}$ & $29 \mathrm{a}$ \\
\hline F-hitung & $71,948^{*}$ \\
\hline
\end{tabular}

Keterangan: $=*$ Berbeda nyata pada taraf $5 \%$, nilai tengah yang diikuti huruf sama tidak berbeda menurut uji BNT pada taraf nyata $5 \%$.

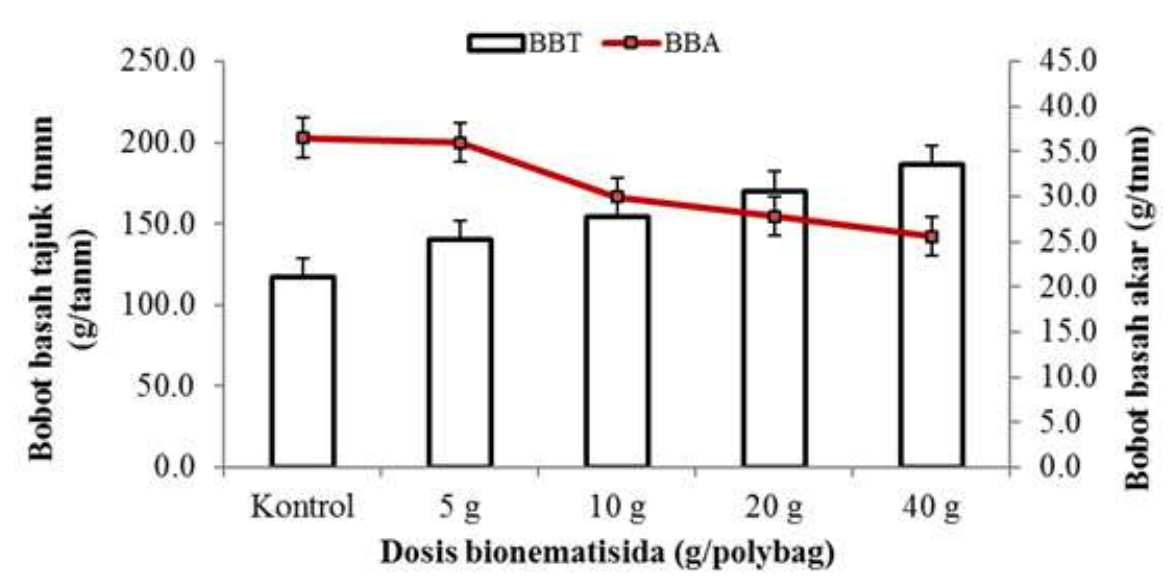

Gambar 3. Bobot brangkasan basah tajuk dan akar tanaman terinfestasi NPAyang diberi perlakuan bionematisida jamur P. lilacinum (Syn. P. lilacinus) isolat BO1TG berbahan pembawa limbah pertanian. 


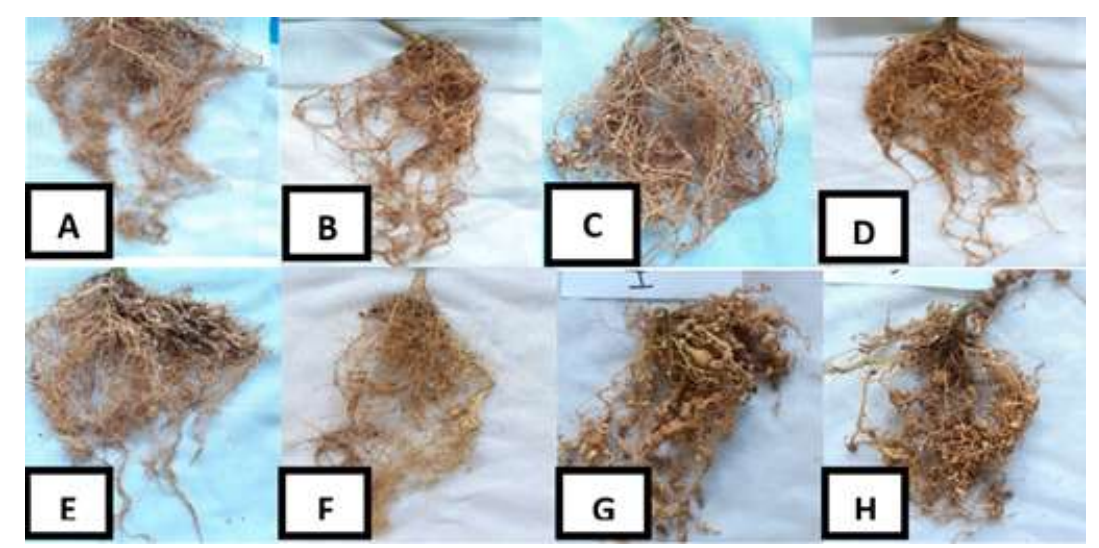

Gambar 4. Kerusakan akar tanaman tomat terserang NPA (Meloidogyne spp.); berdasar skala Zeck (1971 dalam Hay et al., 2014); $\mathrm{A}=$ Skor 1, B=Skor 2, C=Skor 3, D= Skor 4, E Skor 5, F= Skor 6, $\mathrm{G}=$ Skor 7, dan $\mathrm{H}=$ Skor 8 .

Tabel 3. Kerusakan akar tanaman terinfestasi NPA setelah diberi perlakuan bionematisida jamur P. lilacinum (Syn. Paecilomyces lilacinus) isolat BO1TG berbahan pembawa limbah pertanian pada berbagai dosis.

\begin{tabular}{cc}
\hline Perlakuan & Kerusakan akar (Skala Zeck) \\
\hline Kontrol & $7,0 \mathrm{e}$ \\
$5 \mathrm{~g}$ & $5,6 \mathrm{~d}$ \\
$10 \mathrm{~g}$ & $4,6 \mathrm{c}$ \\
$20 \mathrm{~g}$ & $3,0 \mathrm{~b}$ \\
$40 \mathrm{~g}$ & $1,8 \mathrm{a}$ \\
\hline F-hitung & $43,711^{*}$ \\
\hline
\end{tabular}

Keterangan: $=*$ Berbeda nyata pada taraf $5 \%$, nilai tengah yang diikuti huruf sama tidak berbeda menurut uji BNT pada taraf nyata $5 \%$.

infestasi NPA pada tanaman kontrol dan yang diberi perlakuan bionematisida dengan dosis rendah menyebabkan bobot akar meningkat. Sementara itu, pada tanaman tomat yang diberi perlakuan bionematiada dengan dosis $40 \mathrm{~g}$, puru yang terbentuk sedikit dan berukuran kecil, sehingga BBAnya rendah. Tanaman yang akarnya berpuru mengalami hambatan pertumbuhan sehingga BBTnya rendah, tetapi sebaliknya BBA tanaman seperti ini tinggi, seperti yang terjadi pada tanaman kontrol (Gambar 3).

Perlakuan bionematisida juga mempengaruhi jumlah buah (Tabel2). Jumlah buah tanaman terinfestasi NPAyang diberi perlakuan 40 g bionematisida mencapai 29 buah, sedangkan tanaman kontrol hanya menghasilkan rata-rata 5,2 buah per tanaman. Serangan NPAmenyebabkan pertumbuhan tanaman buruk, bunga rontok, sehingga sedikit yang berhasil menjadi buah. Liestiany \& Fikri (2009) menyebutkan bahwa hampir 100\% tanaman tomat di Desa Guntung Manggis, Kecamatan Landasan Ulin Tengah terserang nematoda Meloidogyne spp. sehingga produksinya hanya mencapai $75 \%$ dari produksi optimumnya. Walapun tanaman terinfestasi NPA, perlakuan agensia hayati P. lilacinus dapat menjaga produksi tetap tinggi, produksi meningkat 522,9\%, pada tanaman tembakau, $331,1 \%$ untuk tanaman cabai, dan 172,2\% untuk tanaman kedelai dibandingkan dengan produksi pada tanaman kontrol (Dube \& Smart, 1987). 


\section{Kerusakan Akar}

Hasil analisis ragam menunjukkan bahwa perlakuan bionematisida berpengaruh nyata terhadap kerusakan akar berupa puru yang terbentuk (Tabel 3) dan Gambar 5. Aplikasi bionematisida jamur $P$. lilacinum (Syn. P. lilacinus) isolat BO1TG berbahan pembawa limbah pertanian mempengaruhi kerusakan akar karena NPA (Meloidogyne spp.). Kerusakan akar tanaman kontrol yang tidak diberi perlakuan bionematisida pada skala 7 , nyata lebih tinggi daripada kerusakan akar tanaman yang diberi perlakuan bionematisida. Kerusakan akar rendah skala 1,8 terjadi pada tanaman yang diberi perlakuan bionematisida 40g/tanaman. Hasil penelitian ini sejalan dengan Wiriyadiputra (2002) yang melaporkan bahwa tingkat serangan nematoda terendah terjadi pada tanaman yang diberi bionematisida berbahan aktifjamur P. lilacinus strain 251 dosis $4,00 \mathrm{~g} /$ pohon .

\section{KESIMPULAN}

Perlakuan bionematisida jamur P. lilacinum (Syn. P. lilacinus) isolat BO1TG berbahan pembawa limbah pertanian efektif mengendalikan serangan nematoda puru akar Meloidogyne spp. Kerusakan akar, tanaman tomat terinfestasi Meloidogyne spp. yang diaplikasi bionematisida 40 g per tanaman lebih rendah sehingga pertumbuhan dan produksinya lebih tinggi daripada tanaman yang diberi perlakuan bionematisida dengan dosis 0 - 20 g per tanaman.

\section{UCAPAN TERIMA KASIH}

Ucapan terima kasih disampaikan kepada Bapak I Gede Swibawa dan anggota tim penelitian "Penggunaan Jamur Paecilomyces lilacinus sebagai bionematisida pengendali Meloidogyne spp. pada pertanam jambu kristal: Efikasi formula padat".”yang didanai Direktorat Riset dan Pengabdian Masyarakat (DRPM) dan Direktorat Jenderal Riset dan Pengembangan Kementerian Riset, Teknologi dan Pendidikan tahun 2019 yang telah mendanai dan memfasilitasi penelitian ini.

\section{DAFTAR PUSTAKA}

Agrios, G.N. 2005. Plant Pathology. Academic Press. California.

Aksoy, H. M. \& Mennan, S. 2004. Biological control of Heterodera cruciferae (Tylenchida: Heteroderidae) Franklin 1945 with fluorescent Pseudomonas spp. Journal of Phytopathology. 152: 514-518.

Calvet, C., Pinochet, J., Camprubi, A., Estaun, V. \& Rodriguez-Kabana, R. 2001. Natural chemical compounds against root-lession and root-knot nematodes and side-effects on the infectivity of arbuscular mycorhizal fungi. European Journal of Plant Pathology. 107: 601-605.

Collange, B., Navarrete, M., Peyre, G., Mateille, T., Tchamitchion, M. 2011. Root-knot nematode (Melodogyne) management in vegetable crop production the chailenge of on agronomic system analisis. Crop protection. 30(10): 251-1262. 
Dropkin, V.H. 1991. Pengantar Nematologi Tumbuhan (Edisi Kedua, alih bahasa oleh Supratoyo). Gadjah Mada University Press. Yogyakarta.

Dube, B., \& G.C. Smart, Jr. 1987. Biological Control of Meloidogyne incognita by Paecilomyces lilacinus and Pasteuria penetrans. J. Nematology 19(2): 222-227.

Haryani, S.M. 2018. Identifikasi Molekuler Jamur Purpureocilium lilacinum (Syn. P. lilacinus) dan Uji Patogenitasnya terhadap Meloidogyne spp. pada Tanaman Jambu Kristal. Skripsi. Universitas Lampung. Bandar Lampung.

Hay, F., Striling, G., Walker, G., Keller, K.O., Cobon, J., Vanstone, V., Bulman, S. \& Griffin, D. 2014. Managemet of Root-Knot Nematode in Vegetable Crops Horticulture Australia Ltd. (HAL). Australia.
Liestiany, E \& Fikri, E.N. 2009. Kemampuan Beberapa Tepung Nabati Mencegah Terjadinya Penyakit Puru Akar Tomat. Jurnal Entomology Kalimantan. 3(2): 1-5.

Stirling, G.R. 2014. Biological Control of PlantParasitic Nematodes Wallingford, UK. CAB International. 282 pp.

Winarto, Darnetty \& Liswarni, Y. 2017. Potensi Jamur Paecilomyces isolat lokal Sumatera Barat untuk pengendalian nematoda bengkak akar (Meloidogyne spp.) pada tanaman sayuran. Laporan Akhir Penelitian Unggulan Perguruan Tinggi. Universitas Andalas. Padang.

Wiriyadiputra, S. 2002. Pengaruh Bionematisida Berbahan Aktif Jamur Paecilomyces lilacinus Strain 251 terhadap Serangan Pratyenchis coffeae pada Kopi Robusta. Pusat Penelitian Kopi dan Kakao Indonesia. 8(1): 18-26. 